\title{
PROMOÇÃO DA AUTONOMIA FEMININA DURANTE O PROCESSO PARTURITIVO: INTENCIONALIDADE DAS AÇÕES DE PROFISSIONAIS DA SAÚDE
}

\author{
PROMOTION OF FEMALE AUTONOMY DURING \\ CHILDBIRTH: INTENTIONALITY OF THE ACTIONS OF \\ HEALTH PROFESSIONALS
}

\section{PROMOCIÓN DE LA AUTONOMÍA FEMENINA DURANTE EL PROCESO DE PARTURICIÓN: INTENCIONALIDAD DE LAS ACCIONES DE LOS PROFESIONALES SANITARIOS}

\author{
Thamiza Laureany da Rosa dos Reis ${ }^{1}$ \\ Fernanda Honnef ${ }^{2}$ \\ Stela Maris de Mello Padoin ${ }^{3}$ \\ Valdecyr Herdy Alves ${ }^{4}$ \\ Ívis Emília de Oliveira Souza ${ }^{5}$
}

\begin{abstract}
Como citar este artigo: Reis TLR, Honnef F, Padoin SMM, Alves VH, Souza IEO. Promoção da autonomia feminina durante o processo parturitivo: intencionalidade das ações de profissionais de saúde. Rev baiana enferm. 2021;35:e42149.
\end{abstract}

\begin{abstract}
Objetivo: compreender a intencionalidade das ações dos profissionais de saúde para promoção da autonomia feminina durante a assistência ao parto e nascimento. Método: pesquisa qualitativa fundamentada na fenomenologia social de Alfred Schütz, realizada com 17 profissionais, em hospital universitário no Sul do Brasil. A análise compreensiva foi guiada pelo referencial teórico-metodológico. Resultados: a intencionalidade do agir profissional foram: garantir o melhor para a mulher, o recém-nascido, o profissional e o serviço de saúde durante o processo de parto e nascimento; e ter expectativa de mudanças na atuação profissional em direção a um novo paradigma. Conclusão: os profissionais de saúde agem com a finalidade de alcançar um desfecho favorável a todos os envolvidos e reconhecem a necessidade de mudanças institucionais e dos profissionais para a qualificação da assistência obstétrica, para que se promova a autonomia da mulher nesse cenário.
\end{abstract}

Descritores: Saúde da Mulher. Parto. Autonomia Pessoal. Pesquisa Qualitativa. Pessoal de Saúde.

Objective: to understand the intentionality of the actions of health professionals to promote female autonomy during assistance to labor and delivery. Method: qualitative research based on Alfred Schütz's social phenomenology, carried

\footnotetext{
Enfermeira Obstetra. Mestre em Enfermagem. Enfermeira Obstetra no Hospital Escola da Universidade Federal de Pelotas, Rio Grande do Sul, Brasil. http://orcid. org/0000-0003-4556-673X.

Enfermeira. Mestre em Enfermagem. Universidade Federal de Santa Maria. Santa Maria, Rio Grande do Sul, Brasil. http://orcid.org/0000-0002-1866-16I I.

3 Enfermeira. Doutora em Enfermagem. Professora da Universidade Federal de Santa Maria. Santa Maria, Rio Grande do Sul, Brasil. stela.padoin@ufsm.br. http://orcid.org/0000-0003-3272-054X.

${ }^{4}$ Enfermeiro Obstetra. Doutor em Enfermagem. Professor da Universidade Federal Fluminense. Niterói, Rio de Janeiro, Brasil. http://orcid.gov/0000-000 I-867I5063.

5 Enfermeira Obstetra. Doutora em Enfermagem. Professora da Escola de Enfermagem Anna Nery. Rio de Janeiro, Rio de Janeiro, Brasil. http://orcid.org/0000-00025037-7821.
} 
out with 17 professionals, in a university hospital in southern Brazil. The comprehensive analysis was based on the theoretical-methodological framework. Results: the intentionality of professional action was to ensure the best for the woman, the newborn, the professional and the health service during the process of labor and delivery; and to expect changes in professional performance towards a new paradigm. Conclusion: health professionals act towards achieving an outcome favorable to all involved and recognize the need for institutional and professional changes to qualify obstetric care, in order to promote women's autonomy in this context.

Descriptors: Women's Health. Childbirth. Personal Autonomy. Qualitative Research. Health Personnel.

Objetivo: comprender la intencionalidad de las acciones de los profesionales sanitarios para promover la autonomía femenina durante el parto y la atención al parto. Método: investigación cualitativa basada en la fenomenología social de Alfred Schütz, llevada a cabo con 17 profesionales, en un hospital universitario en el sur de Brasil. El análisis comprehensivo se orientó por el marco teórico-metodológico. Resultados: la intención de la acción profesional era: garantizar lo mejor para la mujer, el recién nacido, el profesional y el servicio de salud durante el proceso de parto y nacimiento; y esperar cambios en el rendimiento profesional hacia un nuevo paradigma. Conclusión: los profesionales de la salud actúan con el propósito de lograr un resultado favorable a todos los involucrados y reconocer la necesidad de cambios institucionales y profesionales para calificar la atención obstétrica, con el fin de promover la autonomía de las mujeres en este escenario.

Descriptores: Salud de la Mujer. Parto. Autonomia Personal. Investigación Cualitativa. Personal de Salud.

\section{Introdução}

A institucionalização da atenção obstétrica modificou as concepções atribuídas ao processo parturitivo, bem como as condutas de profissionais, parturientes e familiares. A qualificação dessa atenção possibilitou a redução de desfechos maternos e neonatais negativos ${ }^{(1)}$, porém, ao priorizar o uso de intervenções e saberes médicos à autonomia da mulher, reforça o distanciamento do processo de seu caráter íntimo, familiar e privado ${ }^{(1)}$. Tendo em vista a prevalência de ações pautadas em um modelo obstétrico tradicional $^{(1-2)}$, estudo com 586 mulheres indicou a manutenção de uma assistência tecnocrática e intervencionista ${ }^{(2)}$.

Dessa forma, devem ser reforçadas ações para concretização das boas práticas de atenção ao parto ${ }^{(3)}$ e dos valores da formação dos novos profissionais de saúde, para que se mantenha os esforços iniciados na década de 70, de âmbito internacional e nacional, para promoção de mudanças, que teve como marco internacional a publicação das boas práticas de atenção ao parto $^{(4)}$. Tais recomendações indicam que as ações dos profissionais têm potencial para promoção do protagonismo das mulheres no cenário obstétrico e na efetivação dos direitos femininos.
O protagonismo perpassa a prévia tomada de consciência pelas mulheres acerca das práticas assistenciais que serão utilizadas. O encorajamento por parte da equipe de saúde propicia que as mulheres reconheçam a parturição como um processo natural e fisiológico, além de evento consciente participativo e resguardado de direitos ${ }^{(3-5)}$. Nesse sentido, a promoção do protagonismo das mulheres e da autonomia pode proporcionar benefícios que se estendem ao recém-nascido e a família ${ }^{(6-7)}$.

Então, faz-se necessário ampliar a visão acerca do parto para além dos aspectos biológicos, contemplando os direitos das mulheres e o estabelecimento de uma atitude emancipatória para a conquista da sua cidadania. A questão que transita entre a norma e a política recebe críticas, pois, a despeito da edição de iniciativas governamentais ancoradas em leis, portarias, pactos e programas no âmbito do Sistema Único de Saúde (SUS), não logram êxito, na mesma medida, no âmbito das ações da garantia de direitos às mulheres ${ }^{(8)}$.

Por isso, este estudo pautou-se na possibilidade de analisar compreensivamente as ações humanas e suas intencionalidades, mediante escuta dos profissionais de saúde envolvidos na 
atenção obstétrica, para responder à questão de pesquisa: Quais são as suas motivações nesse cenário tendo em vista a autonomia feminina?

Diante do exposto, o objetivo deste estudo foi: compreender a intencionalidade das ações dos profissionais para promoção da autonomia feminina durante a assistência ao parto e nascimento.

\section{Método}

Estudo qualitativo com abordagem fenomenológica $^{(9)}$, ancorado na Fenomenologia Social, de Alfred Schütz ${ }^{(9)}$, como suporte teórico-metodológico para a compreensão da ação das pessoas no mundo social, considerando as relações intersubjetivas inscritas em suas experiências cotidianas. As pessoas desenvolvem ações que ocorrem de maneira consciente, pois são intencionais e possuem significados inscritos nas motivações. As ações resultam das experiências no mundo da vida (situação biográfica e bagagem de conhecimentos), fundamentando os projetos ou intencionalidades (motivos para), os quais podem ser apreendidos ${ }^{(9)}$. Para a redação deste estudo foi utilizado o instrumento para relatos transparentes e precisos de pesquisas denominado Consolidated Criteria for Reporting Qualitative Research (COREQ).

O estudo desenvolveu-se no centro obstétrico de um hospital público de referência para a assistência em nível terciário e integrado ao SUS, localizado no Sul do Brasil. Participaram 17 profissionais, que atenderam aos critérios de inclusão: ser profissional da saúde envolvido diretamente na assistência ao parto. O critério de exclusão foi estar afastado das atividades laborais durante a coleta de dados (férias, licença por motivo de saúde, ou outras). Os profissionais foram abordados nesse serviço, em diferentes turnos, momento em que se realizou a exposição dos objetivos e esclarecimentos da pesquisa. Após o aceite em participar da pesquisa, a entrevista foi desenvolvida individualmente em sala reservada no centro obstétrico.

Optou-se pela entrevista fenomenológica ${ }^{(10)}$ para coleta de dados, no período de abril a maio de 2016, e estas foram gravadas. Essa abordagem tem características peculiares, como a empatia e a intersubjetividade entre o sujeito pesquisador e cada participante, para alcançar a compreensão das experiências e vivências ${ }^{(10)}$. Foram utilizadas questões disparadoras abertas, que permitiram a expressão espontânea das vivências dos profissionais, sua situação biográfica e bagagem de conhecimentos. As questões foram construídas com base no quadro teórico de Schütz ${ }^{(9)}$ e testadas nas primeiras entrevistas, permitindo ajustes e adaptação ao problema de pesquisa. Foram aplicadas junto ao participante as seguintes questões: "O que você tem em vista quando assiste mulheres em processo de parturição?"; "Fale-me sobre as ações promotoras do exercício da autonomia feminina que você realiza na assistência ao trabalho de parto e parto."

A análise ocorreu concomitantemente às entrevistas, uma vez que é necessário reconhecer a convergência e suficiência dos significados para o encerramento da coleta de dados, demarcando o alcance do objetivo ${ }^{(11)}$. Desse modo, não houve prévia determinação amostral e encerrou-se essa etapa de campo na 17aㅡ entrevista.

Os dados foram organizados com base na transcrição das entrevistas, seguida de sua leitura e releitura, iniciando-se a análise para identificar as convergências e similaridades ou as significações mais amplas, que indicavam as ações e intencionalidades (motivos para) no estudo em tela, a ação de assistir as mulheres em processo de parturição, tendo em vista a autonomia feminina, e foram separadas e agrupadas conforme a similaridade de sentidos. Para a análise crítica foi feito o agrupamento de trechos que representavam os aspectos afins significativos da ação (objeto deste estudo), compondo-se as categorias concretas com descrição das ações e das intencionalidades correspondentes.

Cabe ressaltar que foi realizado o diálogo entre os resultados da pesquisa, o referencial teórico da fenomenologia social e as evidências científicas relacionadas à temática em estudo. Essa tríade permite uma visão contextualizada e teoricamente embasada do fenômeno estudado, e possibilita que o pesquisador garanta a validade científica, a significação subjetiva da ação 
e a compatibilidade entre as construções do pesquisador e as experiências do sentido comum da realidade social $^{(12)}$.

No desenvolvimento do estudo foram observados os aspectos éticos, conforme Resolução no 466/2012, do Conselho Nacional de Saúde, com aprovação pelo Comitê de Ética em Pesquisa (CEP) com seres humanos da instituição, conforme Parecer n⿳⺈ 1.387.340, de 12 de janeiro de 2016.

\section{Resultados}

A descrição dos participantes será apresentada pela sua situação biográfica, uma vez que este aspecto subsidiou a compreensão das motivações das ações. Dentre os aspectos, estavam sua formação, seu cotidiano e suas relações laborais, bem como a bagagem de conhecimento acerca de autonomia feminina (Quadro 1).

Quadro 1 - Situação biográfica e ações dos profissionais participantes do estudo com a intenção de promoção da autonomia das mulheres. Santa Maria, Rio Grande do Sul, Brasil, 2016

(continua)

\begin{tabular}{|c|c|c|}
\hline $\mathbf{P}$ & Situação Biográfica & Ações para promoção da autonomia \\
\hline P1 & $\begin{array}{l}\text { Enfermeira, } 4 \text { meses } \\
\text { de atuação no serviço, } \\
\text { formada em 2012, realizou } \\
\text { especialização. }\end{array}$ & $\begin{array}{l}\text { Às vezes só fico perto, quieta, para escutar as perguntas delas. } \\
\text { É uma forma de dar autonomia, falar o que ela vai sentir, o } \\
\text { que está acontecendo e o que está sendo feito no corpo dela. } \\
\text { Falo que elas podem caminhar, tomar água, comer e que vão } \\
\text { ficar em um leito com acompanhante. }\end{array}$ \\
\hline $\mathrm{P} 2$ & $\begin{array}{l}\text { Enfermeira, } 6 \text { meses de } \\
\text { atuação no serviço, formada } \\
\text { em } 2013 \text {, realizou doutorado. }\end{array}$ & $\begin{array}{l}\text { Eu procuro orientar sobre o trabalho de parto. Ao mesmo tempo, } \\
\text { eu digo que se elas não quiserem alguma coisa, têm liberdade } \\
\text { para falar. Explico que elas têm liberdade pra escolher ou não } \\
\text { coisas como: tomar água ou comer, se movimentar ou apagar } \\
\text { a luz. }\end{array}$ \\
\hline $\mathrm{P} 3$ & $\begin{array}{l}\text { Enfermeira, } 12 \text { meses de } \\
\text { atuação no serviço, formada } \\
\text { em } 2005 \text {, não realizou pós- } \\
\text { graduação. }\end{array}$ & $\begin{array}{l}\text { É uma questão de orientações, de deixar elas à vontade. Uma } \\
\text { preocupação que eu tenho é perguntar o que elas pensam e o } \\
\text { que querem fazer naquele momento. }\end{array}$ \\
\hline $\mathrm{P} 4$ & $\begin{array}{l}\text { Enfermeira, } 7 \text { meses de } \\
\text { serviço, formada em } 2014, \\
\text { realizou especialização. }\end{array}$ & $\begin{array}{l}\text { Uma das ações que eu posso destacar é: informar a mulher. } \\
\text { Eu acho que a informação é o primeiro passo pra autonomia } \\
\text { [...] Faço orientações em relação ao banho de aspersão, } \\
\text { deambulação, cavalinbo, bola, a posição do parto, a questão } \\
\text { do toque vaginal, do acompanhante e da dieta livre. }\end{array}$ \\
\hline P5 & $\begin{array}{l}\text { Médica, } 12 \text { meses de serviço, } \\
\text { formada em 2014, realizou } \\
\text { especialização. }\end{array}$ & $\begin{array}{l}\text { Para a mulber ter autonomia ela tem que saber o que está } \\
\text { acontecendo. Explicar os riscos, os prejuízos e benefício de tudo } \\
\text { [...] Orientar sobre a possibilidade de caminhar ou fazer ducha, } \\
\text { a bola suiça ou o cavalinho, estimular que o acompanhante } \\
\text { faça uma massagem nas costas ou ajude no sentido moral. }\end{array}$ \\
\hline P6 & $\begin{array}{l}\text { Médica, } 10 \text { meses de serviço, } \\
\text { formada em 2011, realizou } \\
\text { mestrado. }\end{array}$ & $\begin{array}{l}\text { Devemos buscar respeitar a autonomia das mulheres e decidir } \\
\text { por aquilo que não cause risco à vida delas. Esclarecer quais } \\
\text { são as possibilidades, quais são os riscos e então vamos ver o } \\
\text { que ela prefere. }\end{array}$ \\
\hline $\mathrm{P} 7$ & $\begin{array}{l}\text { Técnica de Enfermagem, } 19 \\
\text { meses no serviço, formada } \\
\text { em 2008, não realizou pós- } \\
\text { graduação. }\end{array}$ & $\begin{array}{l}\text { Falo às mulheres que não é porque estão aqui, que têm que } \\
\text { se sujeitar a fazer o que é imposto. Falo que elas têm total } \\
\text { liberdade [...] Também sempre tento deixar o recém-nascido } \\
\text { com a mãe nos primeiros minutos, não largar naquele berço } \\
\text { e causar aqueles traumas, aspirando, colocando colírio e um } \\
\text { monte de coisas. }\end{array}$ \\
\hline P8 & $\begin{array}{l}\text { Técnica de Enfermagem, } 14 \\
\text { meses no serviço, formada } \\
\text { em } 2009 \text {, não realizou pós- } \\
\text { graduação. }\end{array}$ & $\begin{array}{l}\text { Sempre orientamos, explicamos o que pode ser feito e como } \\
\text { pode ser feito, mas é de livre escolha delas [...] Eu sempre digo } \\
\text { que não são obrigadas a nada. O momento é delas, que façam } \\
\text { o que acharem melhor. Claro quando elas podem. }\end{array}$ \\
\hline
\end{tabular}


Quadro 1 - Situação biográfica e ações dos profissionais participantes do estudo com a intenção de promoção da autonomia das mulheres. Santa Maria, Rio Grande do Sul, Brasil, 2016

(conclusão)

\begin{tabular}{|c|c|c|}
\hline $\mathbf{P}$ & Situação Biográfica & Ações para promoção da autonomia \\
\hline P9 & $\begin{array}{l}\text { Médica, } 24 \text { meses de serviço, } \\
\text { formada em } 2012 \text {, realizou } \\
\text { especialização. }\end{array}$ & $\begin{array}{l}\text { Se não tiver nenhuma contra indicação, tem que respeitar e } \\
\text { trabalhar junto. Tentamos com a ajuda da fisioterapia e da } \\
\text { enfermagem, colocar elas no banho, fazer alguns exercicios na } \\
\text { bola, deixar caminhando para a gravidade ajudar [...] Hoje em } \\
\text { dia, com o uso das boas práticas, tentamos ficar mais próximas } \\
\text { das pacientes. }\end{array}$ \\
\hline P10 & $\begin{array}{l}\text { Enfermeira, } 20 \text { anos de } \\
\text { serviço, formada em } \\
\text { 1978, realizou especialização. }\end{array}$ & $\begin{array}{l}\text { Tu tornas a paciente ativa quando a orienta, explica o } \\
\text { trabalho de parto [...] A base da autonomia é sentar e explicar. } \\
\text { Todos os dias tentamos fazer algo diferente, até mesmo através } \\
\text { de um papel que colocamos ali na cabeceira do leito com fotos } \\
\text { de boas práticas. }\end{array}$ \\
\hline P11 & $\begin{array}{l}\text { Fisioterapeuta, } 1 \text { mês de } \\
\text { serviço, formada em } 2015 \text {, } \\
\text { realizou especialização. }\end{array}$ & $\begin{array}{l}\text { Eu oriento primeiro sobre o que vou fazer. Explico qual éo } \\
\text { meu trabalho, quais são as nossas possibilidades e pergunto se } \\
\text { posso ficar. Se elas autorizam, começo a trabalhar, se não, eu } \\
\text { pergunto se mesmo assim elas querem ouvir o que eu tenho } \\
\text { para orientar. A partir do momento que ela aceita a minha } \\
\text { ajuda, já é a autonomia dela. }\end{array}$ \\
\hline P12 & $\begin{array}{l}\text { Médico, } 3 \text { anos de serviço, } \\
\text { formado em 2010, não } \\
\text { realizou pós-graduação. }\end{array}$ & $\begin{array}{l}\text { Encorajamos as mulheres a participarem do trabalho de parto, } \\
\text { a acreditarem que as coisas vão dar certo. }\end{array}$ \\
\hline P13 & $\begin{array}{l}\text { Enfermeira, } 14 \text { anos de } \\
\text { serviço, formada em } 2000, \\
\text { realizou especialização. }\end{array}$ & $\begin{array}{l}\text { Vamos ajudando elas a adquirem conhecimento, esclarecer } \\
\text { dúvidas. Atuamos muito dando as orientações e se fazendo } \\
\text { presente. Às vezes, você fica ali, faz uma massagem nas costas, } \\
\text { pega na mão para ela saber que tem alguém fazendo a escuta } \\
\text { ativa, ouvindo a queixa, ouvindo o choro. Isso ajuda a se } \\
\text { sentirem mais seguras. }\end{array}$ \\
\hline P14 & $\begin{array}{l}\text { Enfermeira, } 16 \text { meses de } \\
\text { serviço, formada em } 2003 \text {, } \\
\text { realizou especialização. }\end{array}$ & $\begin{array}{l}\text { Uma das açôes principais que fazemos são as orientaçôes. Para } \\
\text { elas saberem o que têm direito, saberem que podem dizer "eu } \\
\text { quero assim, eu quero assado". }\end{array}$ \\
\hline P15 & $\begin{array}{l}\text { Técnica de Enfermagem, } 7 \\
\text { anos de serviço, formada } \\
\text { em 2001, não realizou pós- } \\
\text {-graduação. }\end{array}$ & $\begin{array}{l}\text { Procuramos dizer pra elas que não precisam colocar ocitocina } \\
\text { se não quiserem. Dizemos que elas podem caminhar, ir ao } \\
\text { banheiro, gritar e fazer o que quiserem. }\end{array}$ \\
\hline P16 & $\begin{array}{l}\text { Médica, } 20 \text { anos de serviço, } \\
\text { formada em 1989, realizou } \\
\text { doutorado. }\end{array}$ & $\begin{array}{l}\text { A gente estimula a deambular, a ficar na bola, a tomar banho, } \\
\text { essas coisas mais relaxantes e mais estimulantes para o parto. } \\
\text { Se elas [mulheres] quiserem permanecer deitadas, é uma } \\
\text { opção delas. Mas eu sempre gosto de dialogar, fazer a paciente } \\
\text { entender. }\end{array}$ \\
\hline P17 & $\begin{array}{l}\text { Médica, } 21 \text { anos de serviço, } \\
\text { formada em 1990, realizou } \\
\text { especialização. }\end{array}$ & $\begin{array}{l}\text { A gente estimula que a paciente caminhe, fique em bola, faça } \\
\text { exercícios etc. Mas se ela não quiser fazer, não tem que fazer. } \\
\text { Se ela quiser ficar deitada o tempo todo, ela vai ficar deitada o } \\
\text { tempo todo. Ninguém vai obrigá-la a nada. }\end{array}$ \\
\hline
\end{tabular}

Fonte: Elaboração Própria.

Legenda: $\mathrm{P}=$ Participante.

Cada profissional tem seus propósitos e objetivos peculiares enraizados na história singular de suas vidas influenciando suas motivações para realizar ações promotoras do exercício da autonomia das mulheres no processo de parto e nascimento. Então, foram reunidas as sínteses objetivas dos significados da ação que emergiram das experiências dos participantes e mostram a intencionalidade das ações por meio das categorias concretas do vivido ${ }^{(9)}$. Foi apreendido que o profissional tem como intencionalidade: "Garantir o melhor para a mulher, o recém-nascido, 
o profissional e o serviço de saúde durante o processo de parto e nascimento"; e "Intencionalidade de modificar o modelo de atenção obstétrico vigente".

\section{Garantir o melhor para a mulher, o recém- -nascido, o profissional e o serviço de saúde durante o processo de parto e nascimento}

Os profissionais esperam com suas ações estimular a participação ativa da mulher durante o parto, contribuir para que este seja um momento especial e de boas recordações. Agem visando alcançar o melhor para todos os atores sociais envolvidos: a mulher, o recém-nascido, o profissional e o serviço de saúde. Minha motivação é que elas [mulheres] entendam o que
está acontecendo com o próprio corpo e tenham o direito
de escolber o que querem fazer. (P2).

Tenham um bom primeiro encontro, que seja um momento bonito. (P6).

O que me motiva é o desfecho daquele momento ser um nascimento bonito, em que ela se sinta realizada como mulher e como mãe. (P10).

Facilitar o trabalho de parto e ajudar elas a terem um parto menos sofrido. (P8).

Único objetivo pensar no bem estar dela e do feto [...] trabalhamos de uma maneira que seja boa pra elas $e$ para nós. (P9).

Por experiências e por evidências sabe-se que o parto normal é melhor para a paciente e para o bebê. Que a recuperação é melhor e, em termos de custos para o hospital, é uma internação mais rápida. Então faz bem para todo o conjunto: mãe, bebê e hospital. (P12).

\section{Intencionalidade de modificar o modelo de atenção obstétrico vigente}

A modificação do cenário do parto é identificada nas falas dos profissionais, quando expressam a expectativa de modificar a infraestrutura para um espaço acolhedor e favorável à implantação de práticas humanizadas pautadas nas evidências científicas, e até mudanças da atuação profissional na direção de um novo paradigma de assistência.

É necessária uma mudança e, para isso, temos que parar de fazer obstetrícia sem evidências científicas. (P4).

Melhoraria muito se tivessem mais profissionais engajados e um espaço físico melhor. (P6).
Não é algo que eu possa mudar sozinha. Depende de como o serviço é organizado. (P9).

[...] gostaria de oferecer algumas coisas que não posso por que o serviço não funciona assim. (P3).

As coisas estão mudando. São passos de tartaruga, mas chegamos lá. (P10).

[...] não pode continuar igual porque sempre foi assim. (P14).

Pensando na autonomia das mulheres no parto: tem muito que avançar [...] tem que reinventar a roda. (P17).

Tem uma corrente nova de pensamento. Tenbo esperança que as coisas melborem e que a mulher tenha mais liberdade de manifestar sua vontade. (P15).

\section{Discussão}

No presente estudo, infere-se que a bagagem de conhecimento e a situação biográfica dos profissionais constituíram-se como orientadoras de suas ações no cotidiano obstétrico. Dessa forma, a trajetória profissional de todos os participantes do estudo particulariza as suas ações sociais durante a assistência à saúde, pois estão inseridas no mundo da vida social, em relações intersubjetivas, sendo significadas e ressignificadas conforme o tipo de relação estabelecida com o outro ${ }^{(9)}$.

Visando promover a autonomia feminina no processo de parto e nascimento, os profissionais de saúde lançam mão de orientações relativas ao processo parturitivo, como a presença do acompanhante de livre escolha da mulher, as diferentes posições da parturiente no primeiro e segundo períodos do parto, o uso de métodos não farmacológicos para o alívio da dor e a redução do uso de práticas intervencionistas sem a indicação clínica e científica adequada. Estas condutas positivas contribuem para melhorar o atendimento no processo parturitivo ${ }^{(3,13)}$. Ainda, tais condutas são convergentes com as recomendações da Organização Mundial da Saúde (OMS) ${ }^{(4)}$.

Por outro lado, apesar do pouco tempo de formação dos profissionais e a humanização ter ganhado espaço com as diretrizes nacionais de assistência ao parto, a compreensão das ações revela aspectos que refletem a formação profissional pautada no modelo tecnocrático e medicalizado ${ }^{(3,14)}$. Assim, na interpretação da 
fenomenologia ${ }^{(9)}$, ao ingressarem na assistência ao parto, os profissionais adotam uma atitude natural e utilizam os códigos recebidos dos profissionais que já atuam no serviço, o que os faz reconhecer e agir conforme estes, em conformidade com o modelo obstétrico vigente.

A intencionalidade de fazer o melhor para todos os envolvidos é mediada pela relação face a face intersubjetiva, caracterizada por voltar-se ao outro e pela proximidade. Com essa relação demonstram sua aproximação com as expectativas das mulheres, especialmente quando pretendem mediar a vivência do parto como um evento único e especial, considerando-as como dotadas de direitos ${ }^{(9)}$. Entretanto, as concepções acerca desse bem-estar apresentam-se restritas à categoria clínica, reflexo do modelo tecnocrático; isso é corroborado em um estudo que mostra as orientações prescritivas e rotineiras não individualizadas. Todavia, profissionais de saúde visualizam a comunicação como meio de assegurar que os procedimentos sejam seguidos ${ }^{(15)}$.

A satisfação feminina é uma forma indireta de avaliar a qualidade da assistência obstétrica e está associada principalmente à oferta de informações claras e úteis para suas necessidades no parto, ao respeito e à disponibilidade dos profissionais, bem como à sua participação nas decisões ${ }^{(13,16)}$.

Para as mulheres e suas famílias, a concepção e prestação de serviços de boa qualidade precisam ir além da sobrevivência durante o parto e devem dar às mulheres a oportunidade de serem participantes ativas em seus próprios cuidados, pois isso está intimamente ligado ao seu empoderamento $^{(17)}$.

A superação dessas condutas e concepções restritas aos aspectos biológicos depende de políticas públicas que atuem na mudança das práticas de atenção ao parto nos serviços de saúde, nos currículos e nos campos de prática dos cursos de graduação e especialização em Obstetrícia e Neonatologia ${ }^{(14)}$. Deve visar atuação junto aos acadêmicos e profissionais obstetras na avaliação do modelo vigente e seus resultados maternos e perinatais, tendo como subsídio dessa discussão, a legitimidade das evidências científicas $^{(14)}$, como por exemplo, as evidências de revisão sistemática que associam os indicadores diretos para autonomia das mulheres com indicadores que capturam resultados de saúde materna e infantil ${ }^{(18)}$.

$\mathrm{A} \mathrm{OMS}^{(4)}$ ressalva que todas as mulheres, em especial as grávidas, têm direito aos melhores resultados de uma assistência digna e respeitosa e de usufruírem do melhor padrão atingível de saúde física e mental, incluindo saúde sexual e reprodutiva. Para tanto, os sistemas de saúde devem ser organizados e administrados de forma a garantir os direitos humanos das mulheres, responsabilizando-se pela maneira como elas são tratadas durante o parto e implementando políticas claras e normas éticas.

A intencionalidade de promover mudanças na atuação profissional para transformação do modelo obstétrico é evidenciada no agir dos profissionais deste estudo, ao tempo em que visam contemplar a tendência atual de humanização da assistência, que tem como foco o resgate do protagonismo e da autonomia feminina, percebendo o nascimento como evento fisiológico ${ }^{(19-20)}$. Desse modo, agem esperando contribuir futuramente para a qualificação da atenção obstétrica com uma ação projetada, visando o objetivo a ser atingido ${ }^{(9)}$.

As ações com tal intencionalidade são apoiadas pelo Ministério da Saúde por meio da recomendação de estratégias baseadas em evidências ${ }^{(21-22)}$. Entende-se humanização como a valorização dos diferentes atores sociais implicados nos processos da saúde, enfatizando a autonomia e o seu protagonismo. Pressupõe mudanças no modelo de atenção para uma assistência baseada nos direitos sexuais e reprodutivos, democratização das relações de trabalho e fortalecimento da atuação da equipe multiprofissional $^{(22)}$.

Nesse sentido, infere-se que as ações intencionais dos profissionais de saúde com vistas à transformação do modelo obstétrico também inscrevem-se nas suas relações sociais, especialmente nos profissionais com diferentes formações acadêmicas e pontos de vista. Discute-se uma situação presente na realidade brasileira, na 
qual, mesmo sendo reconhecida a necessidade de mudanças em busca da valoração da atenção obstétrica, não se consegue instituir efetivamente o modelo pautado nos princípios da humanização devido à sobreposição do saber médico, alicerçado no modelo biomédico. Defende-se que as características típicas dessa assistência não devem ser fixas, sendo continuamente reestruturadas e motivando novas ações sociais ${ }^{(5-6,15)}$.

Ao projetarem a ação, os profissionais antecipam um comportamento, em que as possibilidades de fazê-lo estão diretamente ligadas ao presente vivido $^{(9)}$, principalmente relacionado às evidências científicas que emergem do movimento pela humanização do parto ${ }^{(4)}$. Não obstante reconhecerem a necessidade de transformação do modelo obstétrico vigente, a promoção da autonomia feminina está limitada às possibilidades de escolha das práticas assistenciais previamente determinadas por protocolos e rotinas do serviço.

Evidenciando o desafio da humanização da assistência obstétrica para os profissionais de saúde, para as instituições e a sociedade, diversas estratégias possíveis esbarram no modelo de atenção predominante, focado no profissional médico, no uso rotineiro de intervenções e na baixa valorização de aspectos psicossociais do parto e nascimento. Contudo, gradativamente, estados e municípios estão aderindo às recomendações ministeriais, reforçadas por meio do programa da Rede Cegonha, e recebendo incentivos financeiros para adequação da infraestrutura e processos de assistência ${ }^{(19,21)}$.

Além da ampliação quantitativa desses serviços, a equipe multiprofissional qualifica a assistência à gestação, ao parto e nascimento. A inserção das enfermeiras obstétricas é estratégica e prioritária, que possibilita (re)direcionar e sensibilizar a equipe multiprofissional ${ }^{(24)}$. Estudos apontam experiências exitosas na refiguração de práticas em saúde desde a sua inserção, permitindo identificar assim o compromisso dessas profissionais com a qualidade da assistência e com os princípios da humanização, das boas práticas e da segurança no parto e nascimento ${ }^{(21,25)}$.

Além do mais, humanizar a assistência à saúde também significa romper com o paradigma biologicista, prescindindo da percepção do sujeito como objeto de intervenção, em razão de uma visão ampliada do ser humano com suas necessidades, sentimentos e condicionantes biológicos, sociais, culturais e econômicos. Isso será possível por meio do redimensionamento dos papéis e poderes dos atores sociais envolvidos na cena do parto e nascimento, devolvendo às mulheres o seu direito de ser mãe com dignidade e segurança; essa realidade é ainda um desafio para todos os profissionais, como promotores de saúde.

Como limitações deste estudo, aponta-se que se buscou retratar a realidade local de um hospital de ensino, referência para partos de alto risco e que tem como características o foco no processo de formação e nas intervenções obstétricas. Por isso, não há a pretensão de generalizar os resultados.

\section{Conclusão}

O estudo possibilitou compreender que os profissionais de saúde agem com a finalidade de alcançar um desfecho favorável para todos: mulher, recém-nascido, profissional e serviço de saúde. Estão orientados por uma formação ancorada no modelo obstétrico tecnocrático e, por vezes, apresentam uma visão restrita a questões biológicas e fisiológicas do parto. Mostrou que há um caminho a ser percorrido para a ampliação da implementação de ações que contemplem a promoção da autonomia da mulher, tendo em vista o fortalecimento do campo contra-hegemônico para a efetiva garantia do direito. Os resultados indicam também a necessidade de se fortalecer o campo das atitudes de cuidados pautadas nas boas práticas de atenção ao parto e diretrizes do MS e da OMS.

\section{Colaborações:}

1 - concepção, projeto, análise e interpretação dos dados: Thamiza Laureany da Rosa dos Reis, Fernanda Honnef e Stela Maris de Mello Padoin;

2 - redação do artigo e revisão crítica relevante do conteúdo intelectual: Thamiza 
Laureany da Rosa dos Reis, Fernanda Honnef, Stela Maris de Mello Padoin, Valdecyr Herdy Alves e Ívis Emília de Oliveira Souza;

3 - aprovação final da versão a ser publicada: Thamiza Laureany da Rosa dos Reis, Fernanda Honnef, Stela Maris de Mello Padoin, Valdecyr Herdy Alves e Ívis Emília de Oliveira Souza.

\section{Referências}

1. Leal MC, Bittencourt SA, Esteves-Pereira AP, Ayres BVS, Silva LBRAA, Thomaz EBAF, et al. Avances en la asistencia al parto en Brasil: resultados preliminares de dos estudios evaluativos. Cad Saúde Pública. 2019;35(7):e00223018. DOI: https://doi.org/10.1590/0102-311X00223018

2. Lopes GDC, Gonçalves AC, Gouveia HG, Armellini CJ. Attention to childbirth and delivery in a university hospital: comparison of practices developed after Network Stork. Rev Latino-Am Enfermagem. 2019;27:e3139. DOI: http://dx.doi. org/10.1590/1518-8345.2643-3139

3. Iravani M, Janghorbani M, Zarean E, Bahrami M. Barriers to Implementing Evidence-Based Intrapartum Care: A Descriptive Exploratory Qualitative Study. Iranian Red Crescent Med J. 2016;18(2):e21471. DOI: 10.5812/ircmj.21471

4. World Health Organization. WHO recommendations: intrapartum care for a positive childbirth experience [Internet]. Geneva (CH); 2018 [cited 2020 Oct 10]. Available from:https:// www.who.int/reproductivehealth/publications/ intrapartum-care-guidelines/en/

5. Carvalho EMP, Amorim FF, Santana LA, Gottems LBD. Assessment of adherence to best practices in labor and childbirth care by care providers working in public hospitals in the Federal District of Brazil. Ciênc saúde colet. 2019;24(6):2135-45. DOI: http://dx.doi. org/10.1590/1413-81232018246.08412019

6. Garcia ER, Yim IS. A systematic review of concepts related to women's empowerment in the perinatal period and their associations with perinatal depressive symptoms and premature birth. BMC Pregnancy Childbirth. 2017;17(2):347. DOI: http://dx.doi.org/10.1186/s12884-017-1495-1

7. Alemayehu YK, Theall K, Lemma W, Hajito KW, Tushune K. The Role of Empowerment in the Association between a Woman's Educational Status and Infant Mortality in Ethiopia:
Secondary Analysis of Demographic and Health Surveys. Ethiopian J Health Sci. 2015;25(4):353-62. DOI: http://dx.doi.org/10.4314/ejhs.v25i4.9

8. Silva AVR, Siqueira AAF. Nascimento e cidadania: entre a norma e a política. Saúde soc. 2020;29(1):e190875. DOI: http://dx.doi. org/10.1590/S0104-12902020190875

9. Schutz A. Sobre fenomenologia e relações sociais. Petrópolis (RJ): Vozes; 2012.

10. Guerrero-Castañeda RF, Menezes TMO, Ojeda-Vargas MG. Características de la entrevista fenomenológica en investigación en enfermería. Rev Gaúcha Enferm. 2017;38(2):e67458. DOI: http://dx.doi.org/10.1590/1983-1447.2017. 02.67458

11. Minayo MCS. Amostragem e saturação em pesquisa qualitativa: consensos e controvérsias. Rev Pesqui Qual [Internet]. 2017 [cited 2020 Oct 10];5(7):1-12. Available from: https://editora.sepq. org.br/index.php/rpq/article/view/82/59

12. Jesus MCP, Capalbo C, Merighi MAB, Oliveira DM, Tocantins FR, Rodrigues BMRD, et al. The social phenomenology of Alfred Schütz and its contribution for the nursing. Rev esc enferm USP. 2013;47(3):736-41. DOI: http:// dx.doi.org/10.1590/S0080-623420130000300030

13. Bohren MA, Berger BO, Munthe-Kaas H, Tunçalp Ö. Perceptions and experiences of labour companionship: a qualitative evidence synthesis. Cochrane Database Sist Rev. 2019;3(3):CD012449. DOI: http://dx.doi.org/10.1002/14651858.CD012449. pub2

14. Niy DY, Oliveira VC, Oliveira LR, Alonso BD, Diniz CSG. Overcoming the culture of physical immobilization of birthing women in Brazilian healthcare system? Findings of an intervention study in São Paulo, Brazil. Interface (Botucatu). 2019;23:e180074. DOI: https://doi.org/10.1590/ Interface. 180074

15. Mgawadere F, Smith H, Asfaw A, Lambert J, Broek NVD. "There is no time for knowing each other": Quality of care during childbirth in a low resource setting. Midwifery. 2019;75:33-40. DOI: https://doi.org/10.1016/j.midw.2019.04.006

16. Côrtes CT, Oliveira SMJV, Santos RCS, Francisco AA, Riesco MLG, Shimoda GT. Implementation of evidence-based practices in normal delivery care. Rev Latino-Am. Enfermagem (Online). 2018;26:e2988. DOI: https://doi.org/10. $1590 / 1518-8345.2177 .2988$ 
17. International Confederation of Midwives. Bill of Rights for Women and Midwives [Internet]. The Hague (NL); 2017 [cited 2020 Sep 15]. Available from: https://www.internationalmidwives.org/ assets/files/definitions-files/2018/06/eng-bill_of_ rights.pdf

18. Pratley P. Associations between quantitative measures of women's empowerment and access to care and health status for mothers and their children: A systematic review of evidence from the developing world. Soc Sci Med. 2016;169:119-31. DOI: https://doi.org/10.1016/j. socscimed.2016.08.001

19. Pereira RM, Fonseca GO, Pereira ACCC, Gonçalves GA, Mafra RA. Novas práticas de atenção ao parto e os desafios para a humanização da assistência nas regiões sul e sudeste do Brasil. Ciênc saúde coletiva. 2018;23(11):3517-24. DOI: http://dx.doi.org/10.1590/1413-812320 182311.07832016

20. Brasil. Ministério da Saúde. Universidade Estadual do Ceará. Humanização do parto e do nascimento [Internet]. Brasília (DF); 2014. (Cadernos HumanizaSUS; v. 4) [cited 2020 Oct 22]. Available from: https://www.redehumanizasus. net/sites/default/files/caderno_humanizasus_v4_ humanizacao_parto.pdf

21. Gama SGN, Viellas EF, Torres JA, Bastos MH, Brüggemann OM, Theme Filha $\mathrm{MM}$, et al. Labor and birth care by nurse with midwifery skills in Brazil. Reprod Health. 2016;13(Suppl 3):123. DOI: http://www.dx.doi.org/10.1186/s12978-0160236-7

22. Mouta RJO, Progianti JM. PROCESS OF CREATING THE BRAZILIAN ASSOCIATION OF MIDWIVES AND OBSTETRIC NURSES. Texto contexto enferm. 2017;26(1):e5210015. DOI: http:// dx.doi.org/10.1590/0104-07072017005210015

23. Miller S, Abalos E, Chamillard M, Ciapponi A, Colaci D, Comandé D, et al. Beyond too little, too late and too much, too soon: a pathway towards evidence-based, respectful maternity care worldwide. Lancet. 2016;388(10058):2176-92. DOI: https://doi.org/10.1016/S0140-6736(16)31472-6

24. Altman MR, Murphy SM, Fitzgerald CE, Andersen HF, Daratha KB. The Cost of Nurse-Midwifery Care: Use of Interventions, Resources, and Associated Costs in the Hospital Setting. Womens Health Issues. 2017;27(4):434-40. DOI: http://dx.doi.org/ 10.1016/j.whi.2017.01.002

25. Sandall J, Soltani H, Gates S, Shennan A, Devane D. Midwife-led continuity models versus other models of care for childbearing women. Cochrane Database Syst Rev. 2016; 4:CD004667. DOI: http://dx.doi.org/ 10.1002/14651858

Recebido: 22 de outubro de 2020 Aprovado: 1 de fevereiro de 2021 Publicado: 27 de abril de 2021

A Revista Baiana de Enfermagem utiliza a Licença Creative Commons - Atribuição-NãoComercial 4.0 Internacional. https://creativecommons.org/licenses/by-nc/4.0/ Este artigo é de acesso aberto distribuído sob os termos da Licença Creative Commons (CC BY-NC). Esta licença permite que outros remixem, adaptem e criem a partir do seu trabalho para fins não comerciais. Embora os novos trabalhos tenham de lhe atribuir o devido crédito e não possam ser usados para fins comerciais, os usuários não têm de licenciar esses trabalhos derivados sob os mesmos termos. 